\title{
PROGRAMA COMPUTACIONAL PARA O DIMENSIONAMENTO DE COLHEDORAS CONSIDERANDO A PONTUALIDADE NA COLHEITA DE SOJA ${ }^{1}$
}

\author{
IACKSON O. BORGES ${ }^{2}$, ANTONIO J. S. MACIEL ${ }^{3}$, MARCOS MILAN ${ }^{4}$
}

RESUMO: A colheita de soja (Glycine $\max$ (L.) Merril) é uma operação crítica que pode sofrer atrasos resultando em perdas na quantidade e na qualidade do material colhido. Embora o valor das perdas seja desconhecido no País, os produtores empregam colhedoras com reserva de capacidade para concluir a operação no menor prazo possível. O excesso de capacidade aumenta os custos fixos e a falta dela aumenta os custos das perdas por atraso e, em ambos os casos, reduzem a renda líquida da operação, ao que se denomina custo de pontualidade. O problema do dimensionamento consiste em ajustar o custo do capital extra investido na capacidade da máquina para garantir a pontualidade e o custo das perdas por atraso, buscando maximizar a renda líquida. Devido à importância da cultura e da pontualidade, o objetivo deste trabalho foi avaliar a influência do atraso no dimensionamento da frota e no custo da operação de colheita. Para tanto, desenvolveu-se um modelo computacional em linguagem Borland® Delphi 5.0, em que a entrada de dados inclui os atributos da região agroclimática, da colhedora e das cultivares de soja. O resultado é a renda líquida como indicador da pontualidade na operação para a colhedora selecionada. O programa foi utilizado para simular cenários numa propriedade na região de Ponta Grossa - PR, e os valores obtidos revelaram que a frota de colhedoras da propriedade opera com capacidade ociosa, produzindo renda líquida abaixo do potencial.

PALAVRAS-CHAVE: máquinas agrícolas, perdas na colheita, simulação - computadores.

\section{COMPUTER MODEL TO SELECT COMBINE HARVESTERS CONSIDERING THE TIMELINESS OF SOYBEAN}

\begin{abstract}
Soybean harvest is considered a critical operation that might suffer some delays causing a reduction in crop yield or quality. Although the value of losses is unknown in the country, combine harvesters with high capacity are applied by the producers and they aim to conclude the operation as fast as possible. If the harvesters have greater capacity than the required, the fixed cost is increased, and if it is the opposite, it might reduce the crop yield. In both cases, there is a decrease in profit, which is called indirect costs. The problem of selecting the agricultural machinery is the commitment between adjusting the cost of the invested extra capital in the machine capacity in order to finish the work in the optimum date and the cost of losses by delaying the operation, seeking to maximize the net profit. Due to the crop importance and the indirect cost caused by the delay in the harvest, the aim of this study was to evaluate the influences suffered because of the delay in the fleet planning and harvest operation costs. For this purpose, a computer model in Borland Delphi 5.0 language was developed where the characteristics of the agro climatic region, the combine harvesters and the soy cultivars are included in the data entrance. The net profit is the result and it works as the indicator for the indirect cost in the operation for the selected combine harvester. The program was used in order to simulate scenarios in a property of Ponta Grossa (PR) region and the values showed that the obtained net profit is below the potential because the combine harvesters of the property work in a lower capacity.
\end{abstract}

KEYWORDS: agricultural machinery, harvest losses, simulation - computers.

\footnotetext{
${ }^{1}$ Extraído da tese de doutorado do primeiro autor.

${ }^{2}$ Eng ${ }^{\circ}$. Agrônomo, Prof. Dr., Universidade Federal do Paraná, Curitiba - PR, Fone: (0XX41) 3350.5624, ioborges@ufpr.br

${ }^{3}$ Prof. Dr., Faculdade de Engenharia Agrícola, FEAGRI/UNICAM, Campinas - SP, amaciel@ agr.unicamp.br

${ }^{4}$ Prof. Dr., Departamento de Engenharia Rural, ESALQ/USP, Piracicaba - SP, macmilan @ esalq.usp.br

Recebido pelo Conselho Editorial em:12-8-2004

Aprovado pelo Conselho Editorial em: 21-3-2006
} 


\section{INTRODUÇÃO}

Uma operação agrícola, para ser efetiva no sistema de produção, deve ser executada no prazo agronomicamente ótimo, e a isso se denomina pontualidade da operação. No planejamento tradicional, a seleção e o dimensionamento de máquinas são baseados no objetivo de completar a operação no menor prazo possível para evitar perdas por atrasos, sobretudo devido ao risco climático e à quebra de equipamentos (HUGHES \& HOLTMAN, 1976). Todavia, isso pode exigir elevada capacidade das máquinas, que resulta na elevação dos custos fixos da operação. Por outro lado, menor capacidade não permite a conclusão da operação no prazo ótimo, resultando em perdas quantitativas e qualitativas da safra (BURROWS \& SIEMENS, 1974; HUAN-WEN \& HUNT, 1985). Em ambos os casos, há redução da rentabilidade do empreendimento, o que se denomina custo de pontualidade. O problema do dimensionamento consiste, pois, em estabelecer uma solução de compromisso entre o custo extra de capital investido na capacidade da maquinaria, como um seguro para garantir a pontualidade, e o custo das reduções pela falta (WHITSON et al., 1981).

No Brasil, cultura da soja se caracteriza pelo uso intenso da mecanização em todas as etapas do sistema de produção, e a colheita é uma operação que pode sofrer atrasos, sobretudo devido às incertezas climáticas. A EMPRESA BRASILEIRA DE PESQUISA AGROPECUÁRIA - EMBRAPA (2002), recomenda que a colheita deva começar tão logo a soja atinja o estádio fenológico R8, pois, a partir deste estádio, a tendência é a deterioração dos grãos e a debulha em intensidade proporcional ao tempo que a soja permanecer no campo. Embora a magnitude dessas perdas seja desconhecida em nosso País, os produtores procuram evitá-las, utilizando frotas de colhedoras com reserva de capacidade para concluir a operação no menor prazo possível, e isso pode apresentar alto custo devido à ociosidade do equipamento. Considerando-se a importância da cultura da soja e da pontualidade nos custos de produção, o objetivo deste trabalho foi avaliar a influência do atraso no dimensionamento de colhedoras e no custo da operação e, para isso, foi desenvolvido um modelo computacional para simular cenários de colheita na região de Ponta Grossa - PR, para determinar a capacidade ótima e identificar possíveis ociosidades da frota de colhedoras utilizada.

\section{MATERIAL E MÉTODOS}

O trabalho foi dividido em três etapas. A primeira consistiu de ensaio de campo para modelar as perdas por atraso na colheita de soja; a segunda, no desenvolvimento do programa, e a terceira na aplicação do modelo para simular cenários de colheita em propriedade da região de Ponta Grossa - PR.

\section{Modelagem das perdas por atraso}

Essa etapa do trabalho consistiu na modelagem das perdas por atraso na colheita de quatro cultivares de soja, obtida a partir de um ensaio de campo conduzido como lavoura comercial na região de Ponta Grossa - PR, na safra 2001-2002, localizado a 50²9'13' 'W e 25 01'36' S e a 869 m de altitude. $\mathrm{O}$ delineamento experimental adotado foi o de blocos ao acaso, com três repetições, seguindo o esquema de parcelas subdivididas, conforme descrito em PIMENTEL-GOMES (2000). Foi considerado como fator $\mathrm{A}$ as cultivares de soja, em número de quatro, compondo as parcelas ou tratamentos. Como fator B, foi considerado as épocas ou atrasos de colheita, em número de dez, compondo as subparcelas ou subtratamentos.

Foram utilizadas as cultivares FT Cometa e M-Soy 5942, ambas de ciclo precoce e crescimento indeterminado; BRS 133, de ciclo semiprecoce, e FT Abyara, de ciclo médio, ambas de crescimento determinado. Atingido o estádio de maturação R8, os subtratamentos, com $675 \mathrm{~m}^{2}$ de área útil $(4,5 \mathrm{x}$ $150 \mathrm{~m}$ ), foram colhidos utilizando-se de colhedora NH TC 55, determinada a massa e amostrados para análise conforme a Norma de Qualidade para Classificação e Comercialização de Soja em Grão estabelecida pela Portaria n⿳0 262/82 do Ministério da Agricultura. Aplicou-se análise de variância, 
segundo PIMENTEL-GOMES (2000), para examinar as diferenças estatísticas dos resultados obtidos no ensaio. Em seguida, desenvolveram-se os modelos de regressão para expressar as perdas de produtividade de soja comercial em função do atraso na colheita de cada cultivar, até o limite de 45 dias, metodologia também utilizada por EDWARDS \& BOELHJE (1980), WITNEY (1988) e VEIGA (2000).

\section{Desenvolvimento do programa computacional}

O programa foi desenvolvido utilizando linguagem de programação orientada ao objeto Borland® Delphi 5.0 e um programa para produção de diagramas da UML (Unified Modeling Language) Rational Rose 2000, buscando interface acessível ao usuário.

O usuário inicia a série de simulações especificando, inicialmente, o cenário de colheita na opção PROPRIEDADE. O sistema requisita a seleção da região agroclimática, o turno de trabalho, a precipitação crítica e o período de simulação. São definidos os atributos da região agroclimática, além da identificação por nome e sigla, o turno de trabalho máximo e o período recomendado para a semeadura da soja. Em seguida, seleciona-se a colhedora, especificando o número de máquinas e a velocidade de trabalho. São atributos da colhedora: a marca, o modelo, a potência do motor, a largura da plataforma e o preço de aquisição. O usuário deve, ainda, definir os talhões a serem colhidos, selecionando as cultivares, a extensão das áreas, datas de semeadura e datas prováveis de início da colheita. São definidos os seguintes atributos das cultivares: o ciclo de maturação, os coeficientes de perdas e produtividade respectivos. O usuário deve, também, especificar os indicadores econômicos do cenário, atribuindo valores ao preço da saca de soja, salário do operador e combustível, vida útil do equipamento e valor residual, taxas de juros, seguro e alojamento e eficiência de campo. Com isso, o sistema dispõe do arquivo temporário da propriedade e está pronto para iniciar o processamento. $\mathrm{Na}$ Figura 1, representa-se o fluxograma de entrada de dados de simulações PROPRIEDADE.

O processamento do cenário PROPRIEDADE inicia com a leitura dos atributos armazenados no arquivo de definições da propriedade e o cálculo da capacidade operacional da frota de colhedoras, segundo a AMERICAN SOCIETY OF AGRICULTURAL ENGINEERS (ASAE, 2000a). Realizada a leitura, o modelo inicia a simulação da colheita nos anos do período selecionado, usando um banco de dados que contém uma série histórica de chuva diária da região agroclimática selecionada e um critério para classificar os dias úteis para a operação no período-calendário, baseado na chuva-limite, conforme descrito em GLASBEY \& McGHECAN (1986) e McGHECAN et al. (1989).

O dia será considerado útil para colheita quando a soma da chuva do dia anterior com a do dia atual for menor que a precipitação crítica especificada do cenário. Assim, o processamento avança a operação através do calendário, a partir da data de início da colheita, num ritmo diário igual à capacidade da frota, calculando as perdas da parcela colhida no dia, usando a função de perdas da cultivar do talhão, até o limite de 44 dias. Concluída a colheita, o sistema calcula o tempo gasto na operação, o custo do serviço mecanizado, as perdas totais devidas ao atraso, o custo de colheita, a renda líquida e o custo unitário do respectivo ano, procedendo a mesma rotina para os demais anos até concluir a série da simulação.

O custo do serviço mecanizado é calculado com base no tempo gasto na operação, utilizando a metodologia descrita pela ASAE (2000b), e os indicadores econômicos pertinentes especificados no cenário. O custo de colheita é calculado pela soma do custo das perdas por atraso com o custo do serviço mecanizado, sendo a renda líquida definida pela diferença entre o potencial de renda da área (atraso nulo) e o custo de colheita. O sistema calcula os valores máximo, mínimo, médio e o desviopadrão das perdas, do custo de colheita, da renda líquida, do custo unitário do serviço dos anos válidos da série simulada, do prazo calendário de colheita e dos dias úteis verificados na série e, em seguida, cria o arquivo de resultados do cenário PROPRIEDADE. O arquivo pode ser recuperado para 
alterações com a leitura dos seus atributos, ou dos seus resultados, para exportação ao Microsoft ${ }^{\circ}$ Excel. Na Figura 2, representa-se o fluxograma do processamento de simulações PROPRIEDADE.

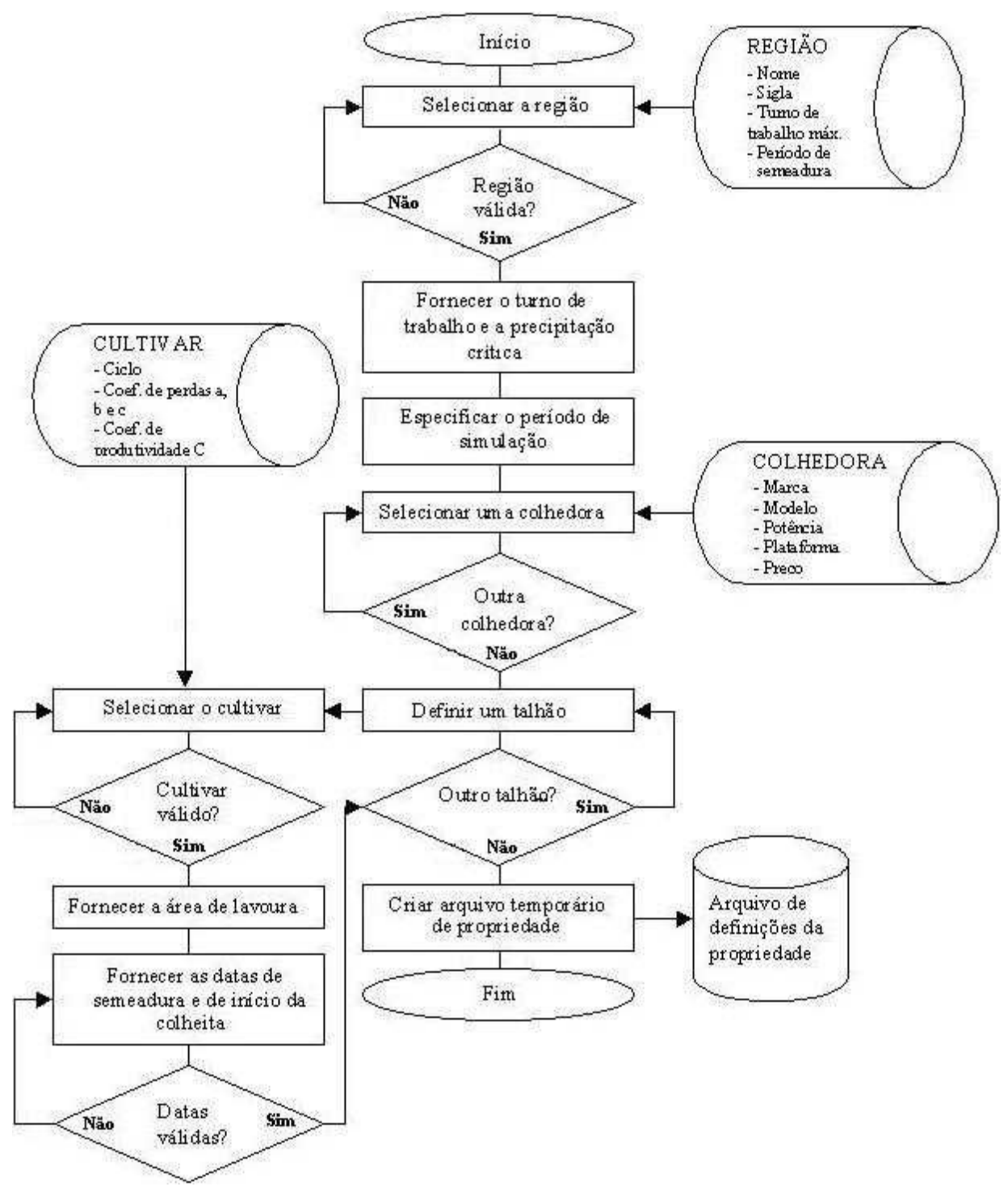

FIGURA 1. Fluxograma da entrada de dados de simulações do cenário PROPRIEDADE. 


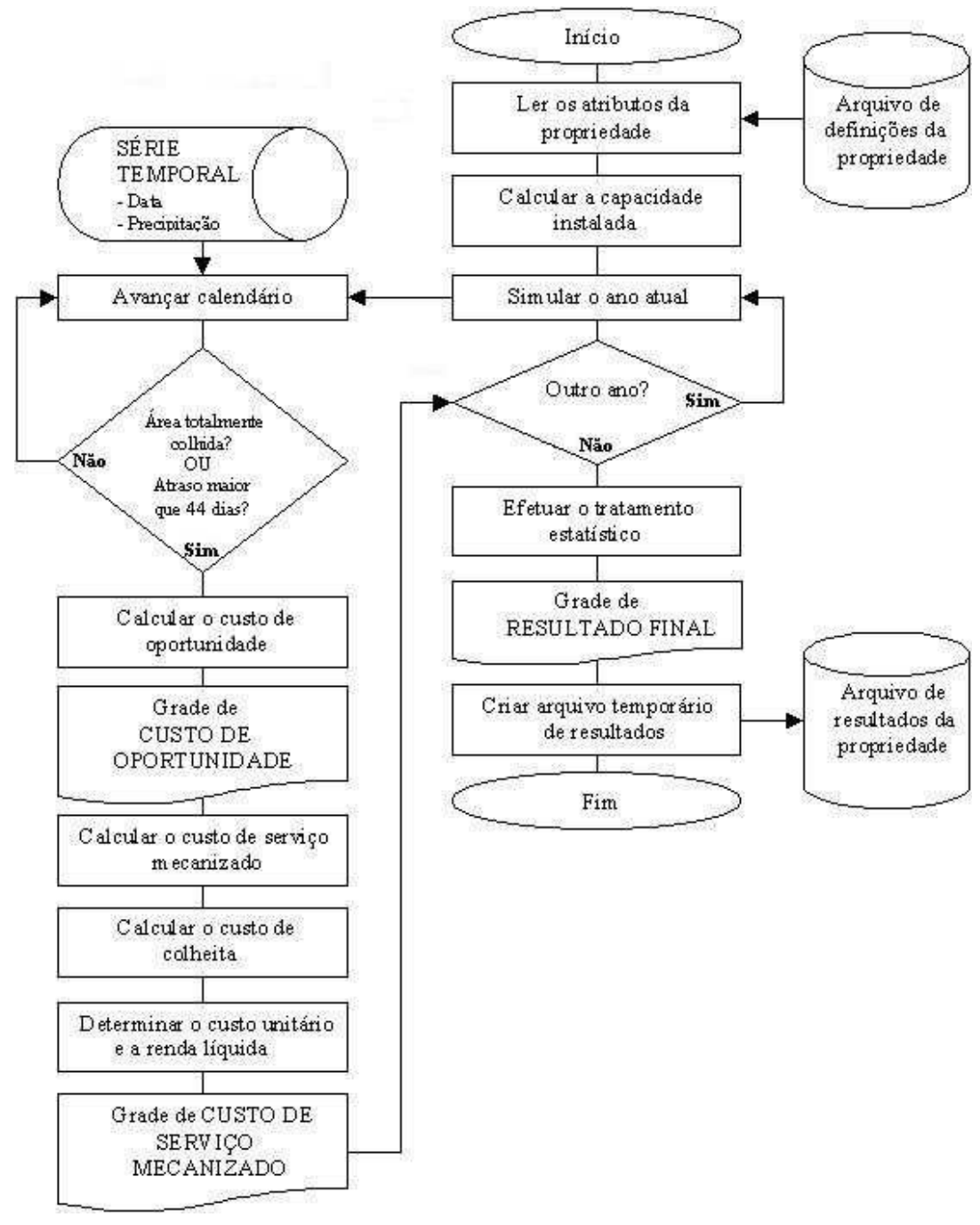

FIGURA 2. Fluxograma do processamento de dados de simulações do cenário PROPRIEDADE.

\section{Cenários e validação do modelo}

Os cenários simulados foram compostos por combinações de cultivares de soja, colhedoras de diferentes capacidades e indicadores econômicos, conforme as condições de contorno especificado na Tabela 1. Utilizou-se de precipitação crítica de $2,5 \mathrm{~mm}$ e série histórica de chuvas diárias entre $1^{\mathrm{O}}$ de fevereiro e 31 de maio, de 1954 a 2003, na região de Ponta Grossa, fornecida pelo Instituto Tecnológico - SIMEPAR. O período de simulação dos cenários foi de 1954 a 2003.

Uma propriedade na região de Ponta Grossa - PR, forneceu o cenário real para a comparação dos resultados das simulações. A área de cultivo do cenário de referência foi de 500 ha de soja composta pelas cultivares FT Cometa + M-Soy 5942 na proporção de 1:1. A frota de colhedoras consistiu de duas unidades de $125,1 \mathrm{~kW}$ e uma unidade de $165,6 \mathrm{~kW}$, com plataformas de 4,8 $\mathrm{m}$ e 7,0 m de largura de corte, respectivamente. Para uma combinação de cultivares, a área de maior renda líquida média anual determina a capacidade ótima da colhedora. 
TABELA 1. Condições de contorno dos cenários simulados.

\begin{tabular}{lcll}
\hline Combinações de Cultivares & Colhedoras & \multicolumn{2}{c}{ Indicadores Econômicos } \\
\hline & & Preço da soja: & US\$ 12,00 por saca 60 kg \\
FT Cometa + M-Soy 5942 & Frota $*$ & Mão-de-obra operador: US\$ 150,00 por mês ** \\
FT Abyara + BRS 133 & $125,1 \mathrm{~kW}$ & Preço do Diesel: & US\$ 0,45 L $\mathrm{L}^{-1}$ \\
FT Cometa + FT Abyara & (plataforma de 4,8 m) & Vida útil: & 10 anos \\
FT Cometa & & Valor residual: & $20 \%$ \\
FT Abyara & $165,6 \mathrm{~kW}$ & Taxa de juros: & $12 \%$ aa \\
& (plataforma de 7,0 m) & Seguro + alojamento: $3,2 \%$ aa \\
& & Eficiência de campo: & $75 \%$ \\
\hline
\end{tabular}

* A frota de colhedoras consistiu de duas unidades de 125,1 kW e uma unidade de 165,6 kW, respectivamente, com plataformas de 4,8 m e 7,0 m de largura de corte. ** Salário de registro. O programa está habilitado para calcular o custo da mão-de-obra de operação incluindo os encargos sociais da ordem de $98 \%$.

\section{RESULTADOS E DISCUSSÃO}

\section{Perdas por atraso na colheita de soja}

Na Figura 3, encontram-se as curvas de tendência de produtividade de soja comercial das cultivares em função do atraso na colheita, obtida nas condições edafoclimáticas da região de Ponta Grossa - PR. Embora não tenha sido possível proceder as colheitas com intervalos regulares num considerável número de subparcelas, devido à interferência do clima, as curvas mostram claramente a redução da produtividade com o atraso em todas as cultivares testadas. Observa-se, porém, que apresentam diferenças na tendência de perdas, sendo esse fato também observado por SEDIYAMA et al. (1972) e LIN \& SEVERO (1982) em ensaios conduzidos para determinar as perdas na produtividade e qualidade de sementes de soja. Assim, as cultivares FT Cometa e M-Soy apresentam menores tendências de perdas por atraso, enquanto o FT Abyara e BRS 133 as maiores tendências, quando comparados entre si. A magnitude dessas perdas, todavia, depende da produtividade potencial, indicando que o rendimento da colheita, sob condições de atraso, pode ser melhorado com o uso de variedades de alta produtividade. BOEHLJE \& EIDMAN (1984) consideram que o custo de pontualidade só é afetado pela produtividade enquanto a ASAE (2000b), além da produtividade, considera também o valor comercial do produto.

Nos modelos de seleção de máquinas baseados na pontualidade (EDWARDS \& BOEHLJE, 1980; OSKAN \& EDWARDS, 1986; WHITNEY, 1988; VEIGA; 2000; ASAE, 2000b), as funções de perdas também resultaram de observações experimentais. BURROWS \& SIEMENS (1974) e CHANCELLOR \& CERVINKA (1974) alertaram que a determinação das perdas é uma tarefa que consome tempo porque devem ser feitos testes e medidas múltiplas, o que limita a quantidade de dados disponíveis. Ademais, resultam de condições específicas de modo que não podem ser utilizados em outros locais.

Ressalte-se, porém, que tais observações resultam de ensaio sob condições específicas na safra 2001-2002. Embora a análise de variância tenha revelado coeficientes aceitáveis (Tabela 2), somente uma série de experimentos nas mesmas condições poderia fornecer curvas de perdas mais confiáveis. 
FT COMETA

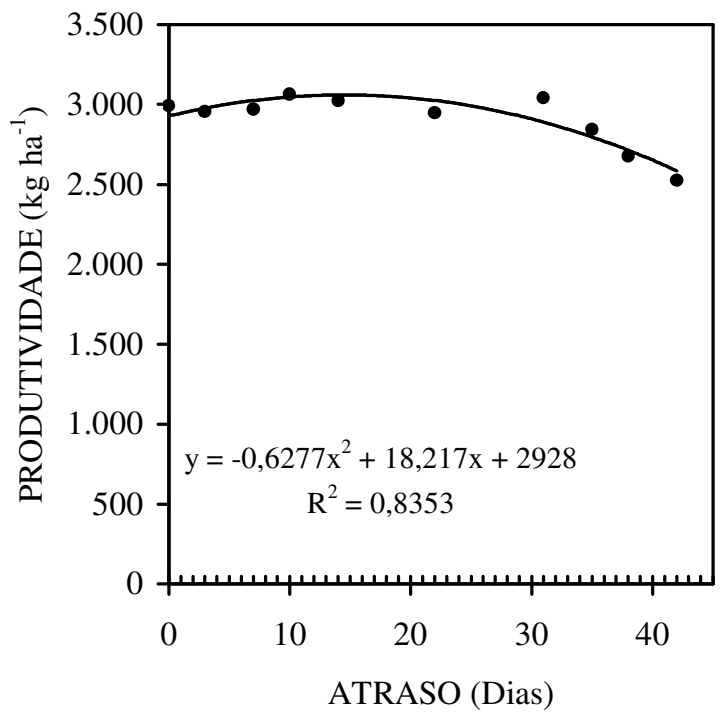

FT ABYARA

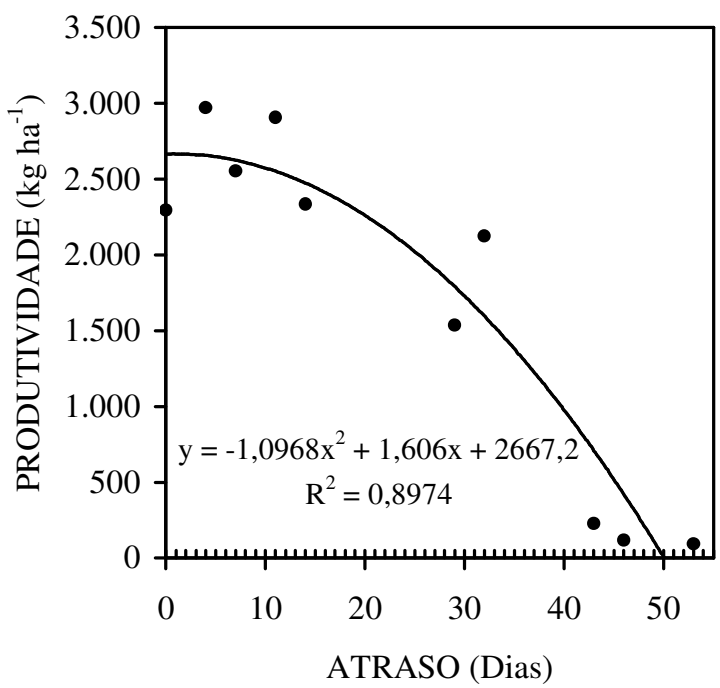

M - SOY 5942

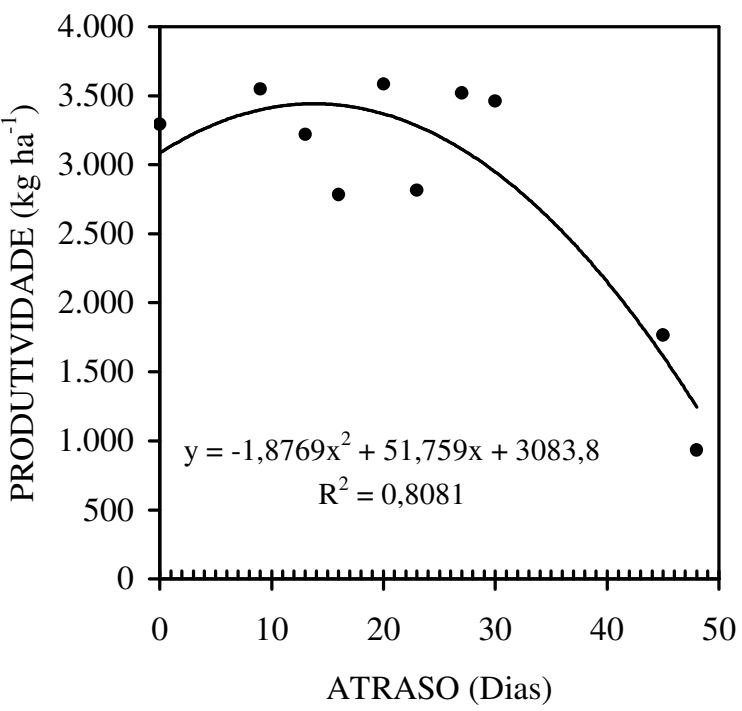

BRS 133

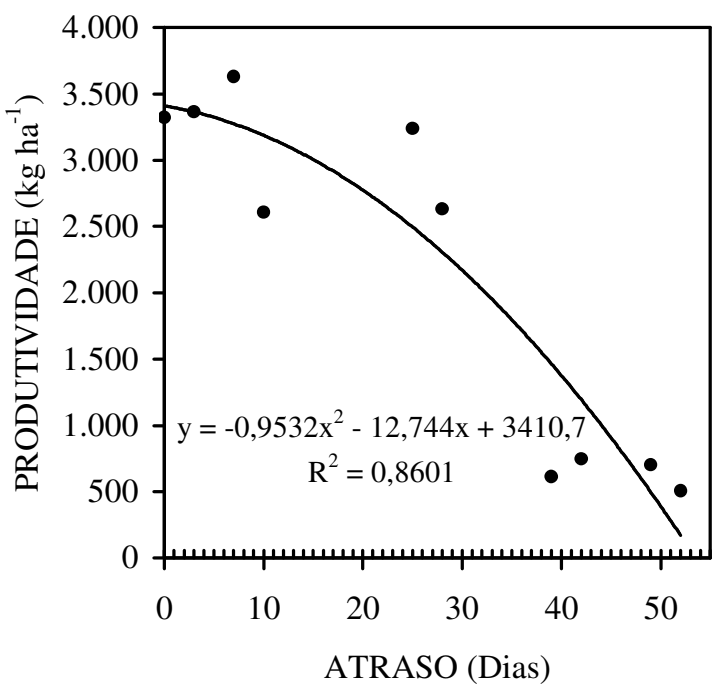

FIGURA 3. Produtividade de soja comercial segundo o atraso na colheita, das cultivares testadas nas condições edafoclimáticas da região de Ponta Grossa - PR. 
TABELA 2. Comparativo das médias de produtividade dos tratamentos e subtratamentos.

\begin{tabular}{cc}
\hline Tratamentos & Média $\left(\mathrm{kg} \mathrm{ha}^{-1}\right)$ \\
\hline FT Cometa & $2.904 \mathrm{~A}$ \\
M-Soy 5942 & $2.891 \mathrm{~A}$ \\
BRS 133 & $2.136 \mathrm{~B}$ \\
FT Abyara & $1.716 \mathrm{C}$ \\
\hline
\end{tabular}

Médias seguidas das mesmas letras maiúsculas nas linhas não diferem significativamente entre si, pelo teste de Duncan, a $1 \%$. C.V. $=13,35 \%$

\begin{tabular}{cc}
\hline Subtratamentos & Média $\left(\mathrm{kg} \mathrm{ha}^{-1}\right)$ \\
\hline $\mathrm{T}_{1}$ & $3.209 \mathrm{~A}$ \\
$\mathrm{~T}_{2}$ & $3.023 \mathrm{AB}$ \\
$\mathrm{T}_{3}$ & $3.045 \mathrm{~B}$ \\
$\mathrm{~T}_{4}$ & $2.976 \mathrm{BC}$ \\
$\mathrm{T}_{0}$ & $2.840 \mathrm{C}$ \\
$\mathrm{T}_{5}$ & $2.842 \mathrm{D}$ \\
$\mathrm{T}_{6}$ & $2.323 \mathrm{E}$ \\
$\mathrm{T}_{7}$ & $1.820 \mathrm{~F}$ \\
$\mathrm{~T}_{8}$ & $1.315 \mathrm{G}$ \\
$\mathrm{T}_{9}$ & $1.014 \mathrm{H}$ \\
\hline
\end{tabular}

Médias seguidas das mesmas letras maiúsculas nas linhas não diferem significativamente entre si, pelo teste de Duncan, a $1 \%$. C.V. $=7,27 \%$

\section{Validação do modelo}

Os resultados das simulações são apresentados na Figura 4, considerando as três categorias de capacidade e cinco combinações de cultivares de soja, ressaltando-se que são limitadas pelas condições de contorno já descritas. A conformação parabólica da renda líquida média anual da operação indica a predominância do custo da capacidade instalada antes do ponto de máxima renda líquida e, após este, a predominância do custo das perdas. Assim, o ponto de renda líquida máxima define a área que corresponde à capacidade ótima do equipamento quanto à pontualidade.

Em uma área cultivada com FT Cometa e M-Soy 5942, a frota maximizaria a renda líquida com 1.900 ha trabalhados. Utilizando a colhedora de $125,1 \mathrm{~kW}$, a renda seria maximizada com 500 ha de lavoura. Para uma colhedora de 165,6 kW, a renda líquida seria maximizada com 900 ha. Ressalte-se que ambas as cultivares revelaram menores tendências de perdas por atraso na colheita. $\mathrm{Na}$ combinação de FT Abyara e BRS 133, cultivares com maiores tendências de perdas, a capacidade da frota seria reduzida para 1.000 ha, enquanto para as unidades de $165,6 \mathrm{~kW}$ e $125,1 \mathrm{~kW}, 500$ e 300 ha, respectivamente. Numa composição intermediária com FT Cometa e FT Abyara, a capacidade da frota subiria para 1.600 ha. Para as unidades de $165,6 \mathrm{~kW}$ e $125,1 \mathrm{~kW}$, a capacidade da frota seria, respectivamente, 700 ha e 400 ha. Porém, se a lavoura constituir-se de apenas uma cultivar, por exemplo, FT Cometa ou FT Abyara, a capacidade da frota seria reduzida para 1.000 ha e 700 ha, respectivamente. Para a unidade de $165,5 \mathrm{~kW}, 500$ ha e 400 ha e, para a unidade de $125,1 \mathrm{~kW}, 300 \mathrm{e}$ 200 ha, apenas, respectivamente.

A capacidade ótima da colhedora depende da combinação de cultivares. Cultivares com menores tendências de perdas por atraso na colheita (menor custo de perdas) demandam capacidade menor (menor custo do serviço) e, por conseguinte, produzem maior renda líquida na operação. Ademais, a renda pode ser potencializada com o uso de composições de cultivares com menor tendência de perdas associadas ao escalonamento da colheita. Na Tabela 3, resumem-se os intervalos de área para uso dos colhedores, visando à maximização de renda líquida, segundo a combinação de cultivares. 
FT COMETA + M-SOY 5942

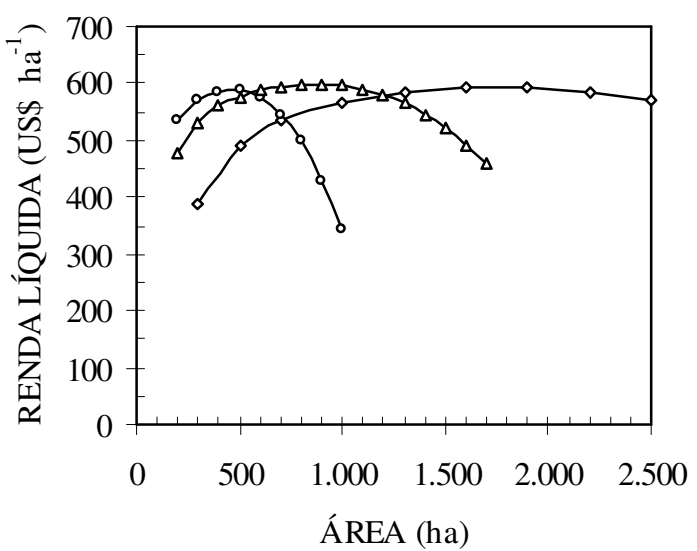

FT COMETA

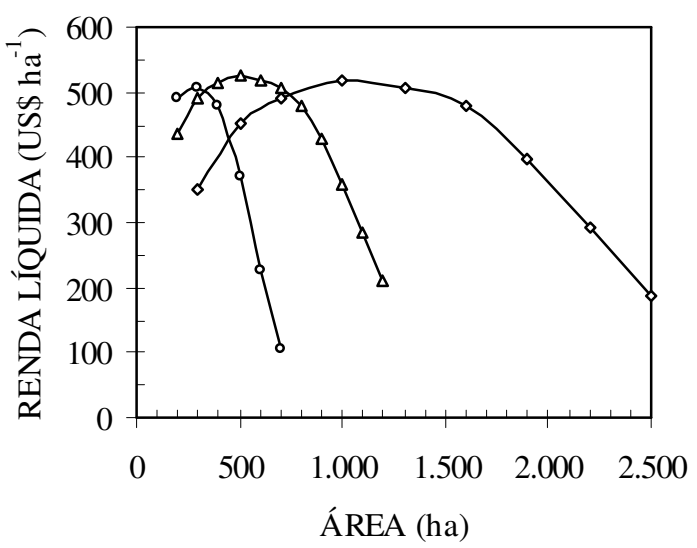

FT COMETA + FT ABYARA

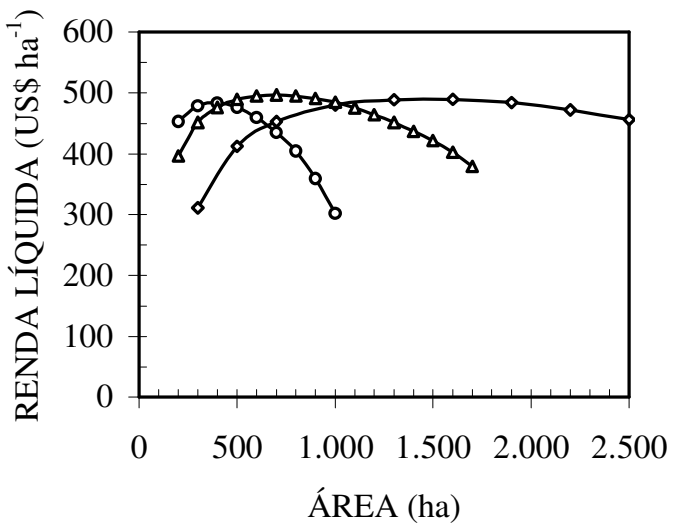

FT ABYARA + BRS 133

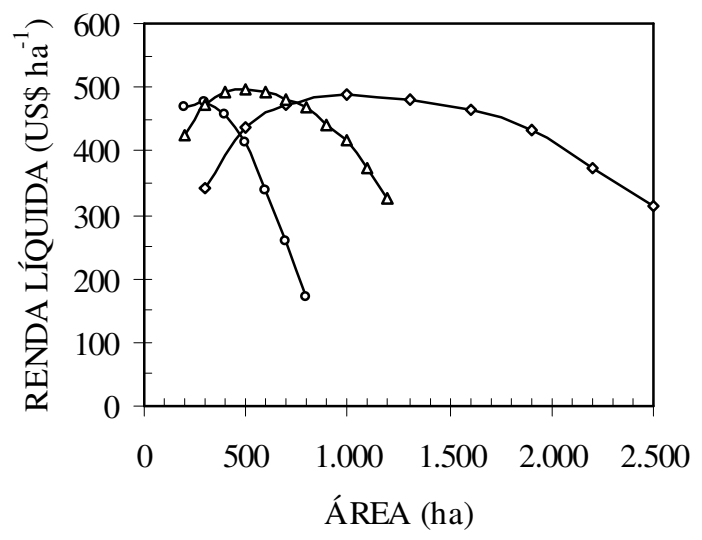

FT ABYARA

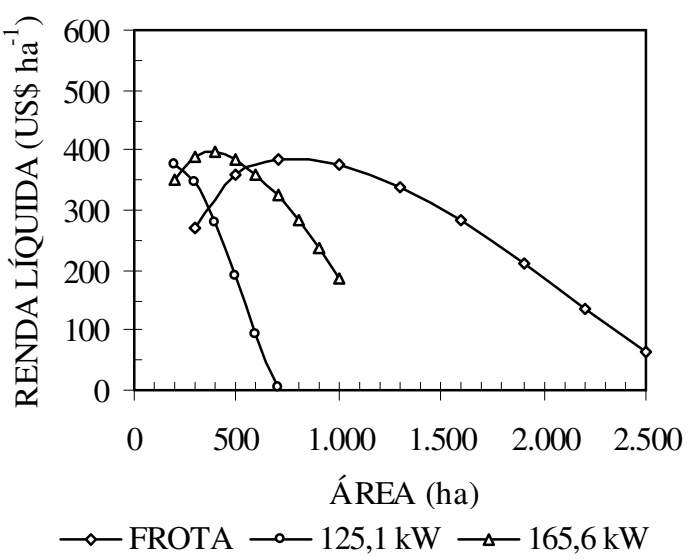

FIGURA 3. Produtividade de soja comercial, segundo o atraso na colheita, das cultivares testadas nas condições edafoclimáticas da região de Ponta Grossa - PR. 
TABELA 3. Intervalos de área (ha) para uso da frota e demais colhedoras.

\begin{tabular}{cccccc}
\hline & \multicolumn{5}{c}{ Combinações de Cultivares } \\
\cline { 2 - 6 } Colhedoras & FT Cometa & FT Abyra & FT Cometa & FT Cometa & FT Abyara \\
& M-Soy 5942 & BRS 133 & FT Abyara & & \\
\hline $125,5 \mathrm{~kW}$ & Área $\leq 500$ & Área $\leq 300$ & Área $\leq 400$ & Área $\leq 300$ & Área $\leq 250$ \\
$165,6 \mathrm{~kW}$ & $600<$ Área $\leq 1.200$ & $300<$ Área $\leq 750$ & $400<$ Área $\leq 1.000$ & $350<$ Área $\leq 750$ & $250<$ Área $\leq 550$ \\
Frota & $1.200<$ Área $\leq 1.900$ & $750<$ Área $\leq 1.000$ & $1.000<$ Área $\leq 1.600$ & $750<$ Área $\leq 1.000$ & $550<$ Área $\leq 700$ \\
\hline
\end{tabular}

Os resultados das simulações demonstram, ainda, que o emprego da frota em 500 ha de lavoura, qualquer que seja a combinação de cultivares, apresenta ociosidade especialmente quando se trata da combinação FT Cometa + M-Soy 5942. Nesse cenário, a frota produz renda líquida de US\$ $492,08 \mathrm{ha}^{-1}$. Sucede que apenas uma unidade de $125,1 \mathrm{~kW}$ seria capaz de colher essa área, produzindo renda líquida de US\$ 586,59 $\mathrm{ha}^{-1}$. Assim, o custo adicional da pontualidade representado pelo uso da capacidade da frota é igual à diferença, ou seja, US\$ 94,51 ha ${ }^{-1}$. A constatação do excesso de equipamentos, em número e capacidade, segundo PARSONS et al. (1981), pode ser explicado pelo fato de que os agricultores realizam o investimento como um seguro para minimizar o tempo consumido em reparos e diluir os riscos de atraso nas operações.

\section{CONCLUSÕES}

As cultivares testadas possuem diferentes tendências de perdas por atrasos na colheita quando comparados entre si, e o modelo desenvolvido mostrou-se adequado para simular os cenários de colheita e determinar a receita líquida respectiva.

As simulações demonstraram que, dependendo da composição de cultivares, a capacidade ótima da colhedora é alterada e que o uso da frota de colhedoras da propriedade-referência apresenta ociosidade em todas as composições de cultivares, considerando uma área de 500 ha de lavoura de soja.

\section{REFERÊNCIAS}

ASAE D497.4. Agricultural machinery management. In: ASAE Standards mar. 99. St. Joseph, 2000a, p.350-7.

ASAE D496.2. Agricultural machinery management. In: ASAE Standards dec 99. St. Joseph, $2000 \mathrm{~b}$. p.344-9.

BOEHLJE, M.D.; EIDMAN, V.R. Farm management. New York: John Wiley \& Sons, 1984. 806 p.

BURROWS, W.C.; SIEMENS, J.C. Determination of optimum machinery for corn-soybean farms. Transactions of the ASAE, St. Joseph, v.17, n.12, p.1130-5, 1974.

CHANCELLOR, W.J.; CERVINKA, V. Timeliness coefficients for rice and factors affecting their value. Transactions of the ASAE, St. Joseph, v.17, n.5, p.841-4, 1974.

EDWARDS, W.; BOEHLJE, M. Machinery selection considering timeliness losses. Transactions of the ASAE, St. Joseph, v.23, n.4, p.810-15, 821, 1980.

EMPRESA BRASILEIRA DE PESQUISA AGROPECUÁRIA - EMBRAPA. Sistemas de Produção 2 - Tecnologias de produção de soja - Paraná 2003. Londrina: Embrapa Soja, 2002. 195 p.

GLASBEY, C.A.; MacGHECAN, M.B. The assessment of combining work-days criteria and forecasting models. Journal of Agricultural Engineering Research, Southampton, v.33, n.1, p.23-31, 1986. 
HUAN-WEN, G.; HUNT, D. Optimum combine fleet selection with power-based models. Transactions of the ASAE, St. Joseph, v.28, n.2, p.364-8, 1985.

HUGHES, H.A.; HOLTMAN, J.B. Machinery complement selection based on time constraints. Transactions of the ASAE, St. Joseph, v.19, n.5, p.812-14, 1976.

LIN, S.S.; SEVERO, J.L. Efeito do atraso da colheita sobre a qualidade da semente e rendimento de soja. Agronomia Sul-Rio-Grandense, Porto Alegre, v.18, n.1, p.47-9, 1982.

McGHECAN, M.B.; SAADOUN, T.; GLASBEY, C.A.; OSKOUI, E.K. Estimation of combine harvesting work-days from meteorological data. Agricultural Engineering, St. Joseph, v.44, n.3. p.6671, 1989.

OSKAN, H.E.; EDWARDS, W.M. A farmer-oriented machinery comparison model. Transactions of the ASAE, St. Joseph, v.29, n.3, p.672-7, 1986.

PARSONS, S.D.; SMITH, T.W.; KRUTZ, G.W. Machinery downtime costs. Transactions of the $A S A E$, St. Joseph, v.23, n.2. p.541-8, 1981.

PIMENTEL-GOMES, F. Curso de estatística experimental. 14. ed. Piracicaba: Pimentel-Gomes, 2000. $477 \mathrm{p}$.

SEDIYAMA, C.S.; VIEIRA, C.; SEDIYAMA, T.; CARDOSO, A.A.; ESTEVÃO, M.M. Influência do retardamento da colheita sobre a deiscência das vagens e sobre a qualidade e poder germinativo das sementes de soja. Experientiae, Viçosa, v.14, n.5, p.117-41, 1972.

VEIGA, C.M. Modelo empírico para a seleção de máquinas agrícolas na cultura da soja considerando a pontualidade na semeadura. 75 f. 2000. Dissertação (Mestrado) - Escola Superior de Agricultura "Luiz de Queiroz”, Universidade de São Paulo, Piracicaba, 2000.

WITNEY, B.D. Choosing \& using farm machines. Edinburgh: Land Technology, 1988. 412 p.

WHITSON, R.E.; KAY, R.D.; LePORI, W.A.; RISTER, E.M. Machinery and crop selection with weather risk. Transactions of the ASAE, St. Joseph, v.24, n.2, p.288-91, 1981. 